\title{
Effect of prewarming in the cold season on thermoregulatory responses during exercise
}

\author{
Masafumi Torii, Masahiro Yamasaki, Takashi Sasaki
}

\begin{abstract}
Objective-To assess whether thermoregulation in the cold season can be affected by prewarming before exercise. Methods-Four healthy non-athletic unacclimatised males were exercised to the same degree in summer and winter on a bicycle ergometer without prewarming (experiment 1) and after prewarming by sitting for $30 \mathrm{~min}$ in a room at $30^{\circ} \mathrm{C}$ (experiment 2). During exercise, sweat production and rectal and skin temperatures were measured continuously.
\end{abstract}

Results-There was seasonal variation in sweating capacity and sensitivity and in heat storage during exercise without prewarming (experiment 1). After the subjects were warmed before exercise, there was no such seasonal variation in their sweat rates during exercise at $30^{\circ} \mathrm{C}$ and $40^{\circ} \mathrm{C}$ (experiment 2 ). In both cases, the sweat rate and skin temperature were dependent on the environmental temperature, and the sweat rate and core temperature were dependent on the workload. In the cold season, sweating sensitivity and evaporative cooling response could be enhanced by thermal stimulation. There was no seasonal difference in the relation between evaporative heat loss and metabolic rate in the two thermal conditions. These values did not differ significantly between winter after prewarming and summer $(P>0.05)$, neither did heat storage and metabolic heat production at various workloads $(P>0.05)$.

Conclusions-There is adaptation of the thermoregulatory mechanisms during temperature acclimatisation. Body warming enhances not only the heat dissipating activity of the thermoregulatory centre but also the induction of peripheral sweat gland activity. Seasonal change of sweat rate in exercising men can be eliminated through a different type of acclimatisation by prewarming in the cold season.

(Br F Sports Med 1996;30:102-111)

Key terms: loss of seasonal change; submaximal exercise; warm up; thermoregulation; thermal balance; metabolic rate; evaporative heat loss.

Several reports have been published on seasonal variation of physiological responses to exercise. These responses include metabolic heat production, ${ }^{1}$ heart rate,${ }^{1}$ forearm blood flow, ${ }^{2}$ maximum aerobic work capacity, ${ }^{3}$ and changes in body temperature. ${ }^{24}$ Shapiro and his coworkers ${ }^{5}$ observed the differences between acclimatisation to heat $\left(40^{\circ} \mathrm{C}\right.$, relative humidity $30 \%$ ) in winter and in summer. The rectal temperature in winter was consistently higher $\left(0.15-0.35^{\circ} \mathrm{C}\right)$ than in the summer experiments. The sweating reaction in summer was characterised by a relatively smaller salt loss despite a greater water loss, while the rise in core temperature was less in summer than in winter. ${ }^{6}$ Araki et $a l^{4}$ have reported on physically inactive and active women, aged 19-22 years, exercising on a bicycle ergometer at three different work intensities for two hours during summer (July-August) and winter (January-February) at an ambient temperature of $30^{\circ} \mathrm{C}$ and a relative humidity of $60 \%$. In both groups, the sweat rates were markedly higher in summer than in winter.

On the other hand, heat acclimatisation studies have established the beneficial effects acclimatisation on thermal responses to dry or wet heat. ${ }^{7-10}$ After heat acclimatisation, sweat rate, sweating efficiency, and sweating sensitivity increased and body core temperature and heart rate decreased compared to the nonacclimatised state. Moreover, during heating of the body in human subjects, skin blood flow in a limb outside the heated area increases, while at the same time the muscle blood flow may decrease. ${ }^{11}$ This must be taken into account when thermoregulatory changes in cutaneous blood flow are assessed by plethysmography of muscular parts of limbs (for example the forearm) or when measuring total blood flow of the extremities. ${ }^{12-14}$ Moreover, Ogawa et al found that local sweat rate of the warmed areas increased with repeated heating of a localised area of the skin. ${ }^{15}$ Clearly it is important to examine human thermoregulatory responses during exercise, especially heat balance regulation. The previous reports, however, do not adequately account for seasonal and temperature acclimatisaton and its mechanisms.

\footnotetext{
Key to abbreviations

$\dot{\mathrm{VO}}_{2} \max =$ maximum oxygen uptake

$\mathrm{RH}=$ relative humidity

$\mathrm{T}_{\mathrm{a}}=$ ambient temperature

$\mathrm{T}_{\mathrm{re}}=$ rectal temperature

$\bar{T}_{s}=$ mean skin temperature

$\overline{\mathrm{T}}_{\mathrm{b}}=$ mean body temperature

$\dot{\mathrm{m}}_{\mathrm{sw}}=$ sweat rate

TSR $=$ total sweat rate

$\Delta \mathrm{TSR}=$ change in total sweat rate

$\mathrm{TSR}_{\mathrm{es}}=\mathrm{TSR}$ during exercise in each season

$\mathrm{TSR}_{\mathrm{an}}=$ annual mean value of $\mathrm{TSR}$

$M=$ metabolic rate

$W=$ external work

$E=$ evaporative heat loss

$R+C=$ radiative and convective heat loss

$S=$ change in heat storage

BSA = body surface area
} 
The purpose of our study was therefore to assess whether sweating capacity and sensitivity in the cold season can be enhanced by thermal stimulation. This study concerns seasonal variation in thermoregulatory responses to exercise and aims to assess the role of thermal balance, and its relation to seasonal acclimatisation. We also tried a quantitative approach to the thermal regulatory mechanisms involved in thermal balance during submaximal exercise under heat stress. Preliminary results were published earlier. ${ }^{16}$

\section{Methods}

SUBJECTS AND GENERAL METHODS

The subjects were four healthy males from Kumamoto, Japan, which is located at $33^{\circ} \mathrm{N}$. Table 1 shows characteristics of the subjects. All were inactive males who had not participated in any regular physical conditioning for several years at least preceding the experiment, and had not been heat acclimatised. The subjects undressed to their underwear in a climatic chamber. The body weights shown in table 1 were measured in the winter experiment, and the annual range of weight was from 800 to $1200 \mathrm{~g}$ in each subject. Before the main experiments, the subjects' maximum oxygen uptake $\left(\mathrm{V}_{2}\right.$ max) was determined by incremental loading and the Douglas bag technique. ${ }^{18}$ Bicycle ergometer tests were carried out by the incremental loading technique with a Monark-type ergometer. The pedalling rate was kept constant at $50 \mathrm{rpm}$ and timed with a metronome. After $2 \mathrm{~min}$ of pedalling with a constant load $\left(600-660 \mathrm{kpm} \cdot \mathrm{min}^{-1}=\right.$ $100-110$ watts), the workload was increased by $150 \mathrm{kpm} \cdot \mathrm{min}^{-1}=25$ watts) every minute up to exhaustion.

Two series of experiments were conducted in a climatic chamber with controlled temperatures at 30 and $40^{\circ} \mathrm{C}$ (ambient temperature, $\mathrm{T}_{\mathrm{a}}$ ) and a relative humidity (RH) of $45 \%$. Wind velocity in the climatic chamber was controlled with $0.8 \mathrm{~m} \cdot \mathrm{s}^{-1}$. The subjects performed bicycle exercise at various work intensities (see table 1). The pedal frequency was kept at $50 \mathrm{rpm}$ using a metronome. Measurements of whole body sweating, rectal temperature $\left(\mathrm{T}_{\mathrm{re}}\right)$, skin temperature $\left(\mathrm{T}_{\mathrm{s}}\right)$, and oxygen uptake $\left(\mathrm{VO}_{2}\right)$ were carried out throughout the experimental period.

The experiments on each individual were conducted at the same time of day to avoid variability attributable to the circadian rhythm of body temperature. ${ }^{19}$ All experiments were carried out between 10:00 am and 1:00 pm, with the order randomised. No heavy muscular activities were performed for $24 \mathrm{~h}$ before any test. On the experimental day, the subjects conducted cycle exercise without taking breakfast.

Seasonal averages of mean outdoor temperature during the following experimental period in Kumamoto City were $2.9^{\circ} \mathrm{C}$ in winter (February); $14.8^{\circ} \mathrm{C}$ in spring (April); $27.6^{\circ} \mathrm{C}$ in summer (August), and $17.2^{\circ} \mathrm{C}$ in autumn (October).

EXPERIMENT 1: SEASONAL VARIATION OF THERMOREGULATORY RESPONSES DURING EXERCISE

The subjects arrived at the laboratory between 8:00 and 8:30 am. They rested for at least 30 min on a chair at the normal (or natural) room temperature for each season: in winter, $10^{\circ} \mathrm{C}$; in spring, $15^{\circ} \mathrm{C}$; in summer, $28^{\circ} \mathrm{C}$; in autumn $18^{\circ} \mathrm{C}$ (see fig 1). During this session, the subjects' clothes were as follows: in summer: underwear, shorts, and a cotton shirt with half length sleeves; in winter: underwear, shorts, a cotton shirt with long sleeves, a V-neck sweater, trousers, socks, and a jacket; in spring and autumn: underwear, a cotton shirt with half length sleeves, trousers, and socks. After resting for $10 \mathrm{~min}$ on a bicycle ergometer, the subjects exercised for $20 \mathrm{~min}$, and afterwards stayed on the bicycle ergometer for more than $10 \mathrm{~min}$. All experiments were carried out in a climatic chamber where the $T_{a}$ was maintained at $30^{\circ} \mathrm{C}$, and $\mathrm{RH}$ at a constant $45 \%$. The experiments were performed repeatedly in February, April, August, and October. The bicycle ergometer was placed on a Potter bed scale (automatic weight loss indicator), and the workload was about $40 \%$ of $\mathrm{VO}_{2}$ max in each subject.

EXPERIMENT 2: EFFECT OF PREWARMING IN WINTER ON THERMOREGULATORY RESPONSES TO SUBMAXIMAL EXERCISE

Experiment 2 consisted of 48 trials using three males, and this experiment was carried out from January to early February and in August in the season following that in which experiment 1 was conducted. The same subjects as in experiment 1 exercised moderately for 20 min after warming (sitting on a chair for $30 \mathrm{~min}$ in a room at $30^{\circ} \mathrm{C}$ ). The experimental technique and procedures and the environmental conditions were the same as for experiment 1 (see fig 1B).

After the prewarming, the subjects performed exercise at the same work intensity as in experiment 1 . Exercise testing was carried out at two different workloads, $60 \%$ and $80 \%$ of $\mathrm{VO}_{2}$ max, at $\mathrm{T}_{\mathrm{a}}$ of $30^{\circ} \mathrm{C}$, and at the same workloads at a $\mathrm{T}_{\mathrm{a}}$ of $40^{\circ} \mathrm{C}$ (see fig $1 \mathrm{C}$ ). In August, the same experiments were conducted

Table 1 Physical characteristics of the subjects and their submaximal work loads

\begin{tabular}{|c|c|c|c|c|c|c|c|c|}
\hline \multirow[t]{2}{*}{ Subject } & \multirow{2}{*}{$\begin{array}{l}\text { Age } \\
\text { (years) }\end{array}$} & \multirow{2}{*}{$\begin{array}{l}\text { Height } \\
(\mathrm{cm})\end{array}$} & \multirow{2}{*}{$\begin{array}{l}\text { Weight } \\
(\mathrm{kg})\end{array}$} & \multirow{2}{*}{$\begin{array}{l}B S A \\
\left(m^{2}\right)\end{array}$} & \multirow{2}{*}{$\begin{array}{l}\mathrm{VO}_{2} \max \\
\left(\mathrm{ml}^{\prime} \cdot \mathrm{kg}^{-1} \cdot \mathrm{min}^{-1}\right)\end{array}$} & \multicolumn{3}{|c|}{$\%$ of $\dot{V O}_{2} \max$ (watts) } \\
\hline & & & & & & $40 \%$ & $60 \%$ & $80 \%$ \\
\hline $\begin{array}{l}\text { A } \\
\text { B } \\
\text { C } \\
\text { D }\end{array}$ & $\begin{array}{l}28 \\
30 \\
28 \\
22\end{array}$ & $\begin{array}{l}165 \\
185 \\
166 \\
167\end{array}$ & $\begin{array}{l}63 \\
86 \\
68 \\
55\end{array}$ & $\begin{array}{l}1 \cdot 70 \\
2 \cdot 11 \\
1 \cdot 77 \\
1 \cdot 62\end{array}$ & $\begin{array}{l}43.7 \\
31.6 \\
38.5 \\
51.4\end{array}$ & $\begin{array}{l}60 \\
60 \\
60 \\
80\end{array}$ & $\begin{array}{r}90 \\
90 \\
110\end{array}$ & $\begin{array}{r}125 \\
\overline{125} \\
140\end{array}$ \\
\hline
\end{tabular}

Body surface area (BAS) was estimated by Takahira's equation. ${ }^{17}$ Maximum oxygen uptake $\left(\mathrm{V}_{2}\right.$ max $)$ was determined by a bicycle ergometer and modified technique of Miyamura and Honda. ${ }^{18}$ 


\section{Experimental protocol}

Experiment 1 Four season experiment

Normal temperature in the room

\begin{tabular}{|c|c|c|c|}
\hline \multicolumn{2}{|l|}{1} & \\
\hline $\begin{array}{l}\text { Winter, } 10^{\circ} \mathrm{C} \\
\text { Spring, } 15^{\circ} \mathrm{C} \\
\text { Summer, } 28^{\circ} \mathrm{C} \\
\text { Autumn, } 18^{\circ} \mathrm{C}\end{array}$ & Rest & $\begin{array}{c}\text { Exercise } \\
40 \% \dot{\mathrm{VO}}_{2} \text { max }\end{array}$ & Recovery \\
\hline $\begin{array}{l}\text { Sitting on a chair } \\
\text { and wearing } \\
\text { seasonal clothing }\end{array}$ & 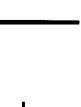 & $\begin{array}{l}\text { Sitting on a bicycle ergometer } \\
\text { Upper body - nude } \\
\text { Lower body - trunks }\end{array}$ & \\
\hline 30 & & 20 & 15 \\
\hline
\end{tabular}

Time (min)

Experiment 2 Prewarming experiment (i)

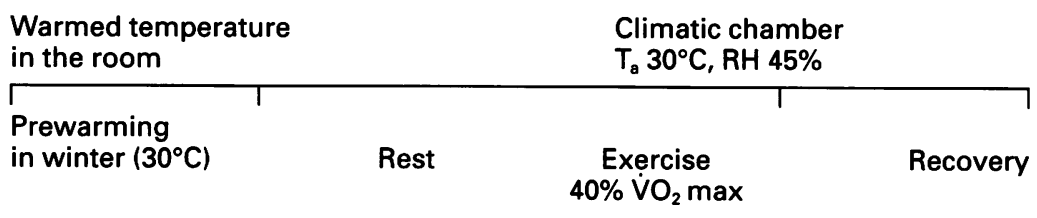

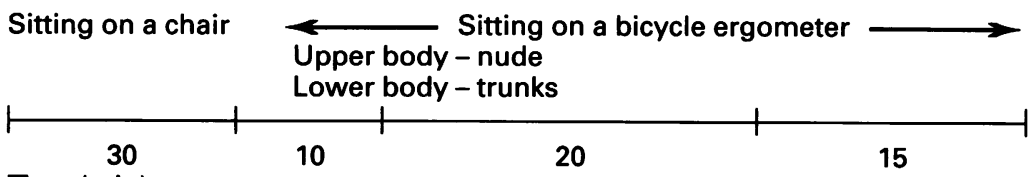

Time (min)

Experiment 2 Prewarming experiment (ii)

(C)

\begin{tabular}{|c|c|}
\hline $\begin{array}{l}\text { Warmed temperature } \\
\text { in the room (winter) } \\
\text { Normal temperature } \\
\text { in the room (summer) }\end{array}$ & $\begin{array}{l}\text { Climatic chamber } \\
\mathrm{T}_{\mathrm{a}} 30^{\circ} \mathrm{C} \text { or } 40^{\circ} \mathrm{C}, \mathrm{RH} 45 \%\end{array}$ \\
\hline $\begin{array}{l}\text { Prewarming } \\
\text { in winter }\left(30^{\circ} \mathrm{C}\right) \\
\text { summer, } 28^{\circ} \mathrm{C}\end{array}$ & $\begin{array}{l}\text { Exercise } \\
40 \%, 60 \% \text {, or } 80 \% \mathrm{VO}_{2} \max \\
\text { or rest }\end{array}$ \\
\hline $\begin{array}{l}\text { Sitting on a chair } \\
\text { wearing seasonal } \\
\text { clothing (summer) }\end{array}$ & $\begin{array}{l}\text { Sitting on a bicycle } \longrightarrow \\
\text { ergometer } \\
\text { Upper body - nude } \\
\text { Lower body - trunks (summer) }\end{array}$ \\
\hline \multicolumn{2}{|c|}{$\begin{array}{l}\text { Upper body - nude } \\
\text { Lower body - trunks (winter) }\end{array}$} \\
\hline $\begin{array}{c}30 \\
\text { Time }(\mathrm{min})\end{array}$ & 20 \\
\hline
\end{tabular}

Fig 1 Experimental protocol. (A) Subjects clothed and sitting for $>30$ min at the normal (natural) ambient room temperature in each season. After sitting on a chair, they exercised on a bicycle ergometer at light intensity $\left(40 \%\right.$ of $\mathrm{VO}_{2} \max$ ) at $30^{\circ} \mathrm{C}$ ambient temperature. (B) This experiment was carried out from fanuary to early February (winter) and August (summer). In winter the experiment was conducted after prewarming by sitting on a chair for 30 min at $30^{\circ} \mathrm{C}$ ambient temperature in trunks only. (C) This experiment was carried out from fanuary to early February (winter) and August (summer) of the next year. Exercise testing at heavy workloads was added in this experiment.

without prewarming, because of activated sweating sensitivity in the subjects. ${ }^{20}$ The adequacy of the subjects', which were $40 \%$, $60 \%$, and $80 \%$ of $\mathrm{VO}_{2}$ max, were confirmed by a preliminary experiment.

Heat exposure was given on the basis of published reports: acclimatisation of men working in both dry and wet heat is achieved after several days of heat exposure, ${ }^{79}{ }^{10}$ and the acclimatisation is characterised by an increase in sweat rate and a reduction in rectal and skin temperature. $^{810}$
MEASUREMENTS AND ESTIMATIONS

Sweating, $T_{r e}$ and $T_{s}$ were measured simultaneously. Sweating was monitored continuously using a bed scale (J A Potter Co, model $33 \mathrm{~B}$, sensitivity $\pm 1.0 \mathrm{~g}$ ) with an automatic electronic weight change indicator. The optimal curve was drawn through the weight record for each experiment and the rate of whole body weight loss was then calibrated before each experiment. ${ }^{21}$ To estimate sweat rate $\left(\mathrm{m}_{\mathrm{sw}}\right)$ and total sweat rate (TSR), respiratory weight loss was estimated as described by Mitchell et $a .^{22}$ Total sweat rate was also displayed as a relative value. The changing rate ( $\Delta$ TSR) against the annual mean value of TSR during exercise for all four seasons was calculated by the following equation:

$\Delta \mathrm{TSR}=\left(\mathrm{TSR}_{\mathrm{es}}-\mathrm{TSR}_{\mathrm{an}}\right) / \mathrm{TSR}_{\mathrm{an}} \times 100$

where $\mathrm{TSR}_{\mathrm{es}}=\mathrm{TSR}$ during exercise in each season and $T S R_{a n}=$ the annual mean value of TSR.

In experiment 2, dripping, where secreted sweat formed droplets on the body surface without evaporating, occurred at a workload of $80 \% \mathrm{VO}_{2}$ max at $\mathrm{T}_{\mathrm{a}}$ of $40^{\circ} \mathrm{C}$ in both summer and winter. Non-effective sweating was indirectly estimated from the increase in weight of subjects' underwear caused by absorbed sweat. In this experiment, the subjects' body weight was checked with a bed scale and their total sweat rates were calculated from body weight before and after the exercise. "Effective sweating" (sweat efficiency) is described by Houdas and Ring ${ }^{23}$ as follows:

Sweating efficiency = rate of sweat evaporation/ rate of sweat production

Rate of sweat evaporation - effective sweating - was indirectly estimated by equation (2) below.

The temperatures of seven locations of skin surface and $T_{\mathrm{re}}$ at a depth of $10-12 \mathrm{~cm}$ from the anus were recorded spontaneously every minute by a copper-constantan thermocouple recording system (AM-300, Ohkura Electric) with an accuracy of $0.05^{\circ} \mathrm{C}$ throughout the experimental period. Mean skin temperature $\left(\bar{T}_{\mathrm{s}}\right)$ and mean body temperature $\left(\overline{\mathrm{T}}_{\mathrm{b}}\right)$ were calculated by Hardy and DuBois' equation ${ }^{24}$ and Stolwijk and Hardy's equation, ${ }^{25}$ respectively.

In order to estimate metabolic rate $(M)$, oxygen consumption was determined by the Douglas bag technique at rest and $2 \mathrm{~min}$ before the end of exercise. Expired gas volume was measured with a gas meter (WT-10, Shinagawa), and the gas samples were immediately analysed for oxygen and carbon dioxide concentrations with a Beckman F-3 analyser and a Horiba MCD-L analyser, respectively. No measurement of $\dot{\mathrm{VO}}_{2}$ was taken in experiment 1 .

The thermoequilibrium during rest and exercise was calculated from the following equation:

$H=M-W=E \pm(R+C) \pm S$

where, $H=$ total heat production, $M=$ metabolic rate, $W=$ external work, $E=$ evaporative 
heat loss, $R+C=$ radiative and convective heat loss, and $S=$ change in heat storage of the body. $M$ was estimated by the equation, $M=\dot{\mathrm{VO}} \mathrm{O}_{2} \pm 5 \cdot 0 \pm 60 / \mathrm{BSA}$, where $\dot{\mathrm{VO}}_{2}=$ oxygen consumption in litres $\mathrm{min}^{-1}, 5 \cdot 0$ (or $\left.4 \cdot 8\right)=$ caloric value produced by consumption of $1 \cdot 0$ litre of oxygen during exercise (or at rest) in $\mathrm{kcal}$, and BSA=body surface area. $E$ was estimated from the assumption that $0.58 \mathrm{kcal}$ of heat is lost for $1.0 \mathrm{~g}$ of water evaporated from the skin surface. $W$ was calculated by Nielsen's equation. ${ }^{26}$ Heat exchange by radiation $(R)$ and convection $(C)$ were calculated using the Fanger's ${ }^{27}$ and Nishi and Gagge's ${ }^{28}$ formulas, respectively. For estimating $S$, we used Stolwijk and Hardy's equation. ${ }^{25}$ In the present study the values of thermal balance were converted in $\mathrm{W} \cdot \mathrm{m}^{-2}$ of the body surface.

STATISTICAL ANALYSIS

The values are given as mean (SEM). Statistically significant differences between mean values were assessed by paired Student's $t$ test, one way (season and individual) or three way analysis of variance ANOvA (season $\times$ $T_{a} \times$ workload). A probability level of 0.05 or less was accepted as a significant difference.

\section{Results}

EXPERIMENT 1: SEASONAL VARIATION OF THERMOREGULATORY RESPONSES DURING EXERCISE

In summer, as soon as the subjects started to exercise, onset of sweat secretion was observed in all experiments. In winter sweat secretion did not occur until after a few minutes. The mean $\dot{\mathrm{m}}_{\mathrm{sw}}$ during exercise was higher in summer than in winter, at $5 \cdot 2(0.6) v 3 \cdot 2(0.4) \mathrm{g} \cdot \mathrm{min}^{-1}$ $(\mathrm{P}<0.01)$. Average values of TSR were 108 $(15 \cdot 7), 139(14.9), 178(26 \cdot 2)$, and 142 $(11 \cdot 7) \mathrm{g} \cdot \mathrm{m}^{-2} \cdot \mathrm{h}^{-1}$ in winter, spring, summer, and autumn, respectively $(P<0.01$, one way ANOVA). There were $\triangle \mathrm{TSR}$ values of $-25 \cdot 8$ $(4 \cdot 3) \%$ in winter and $+21 \cdot 5(5 \cdot 0) \%$ in summer $(\mathbf{P}<0.01)$, with an annual range of 47.7 $(4 \cdot 7) \%$. Increased $T_{r e}$ caused by exercise was significantly higher in winter than in summer. In winter, $S$ was positive but in other seasons it was negative. There were significant differences between summer and winter values of $S$ : $-11 \cdot 1(4 \cdot 5) v 17 \cdot 5(8 \cdot 6) \mathrm{W} \cdot \mathrm{m}^{-2}$, respectively.

EXPERIMENT 2: EFFECT OF PREWARMING IN WINTER ON THERMOREGULATORY RESPONSES TO SUBMAXIMAL EXERCISE

The results in experiment 1 and of light exercise in experiment 2 are summarised in table 2. When the same thermal stimulus was given by having a room temperature of $30^{\circ} \mathrm{C}$ for $30 \mathrm{~min}$ (prewarming) before exercise in winter, there was no seasonal variation in the sweating response to the exercise. There were no significant differences between mean $\dot{\mathrm{m}}_{\mathrm{sw}}$ and TSR and $\triangle T S R$ in summer and winter following prewarming ( $P>0.05)$. The annual range of $\triangle T S R$ change in experiment 1 (based on data in winter) and in experiment 2 (based on data in winter after prewarming) was $47 \cdot 7(4 \cdot 7) \%$ and $25 \cdot 5(5 \cdot 8) \%$, respectively $(\mathrm{P}<0.01)$. The annual range of $\Delta \mathrm{TSR}$ in experiment 2 decreased by $46 \%$ in comparison with experiment 1 .

Figure 2 shows the changes of $\mathrm{T}_{\mathrm{re}}$ and $S$ caused by exercise in various seasons. There was no significant difference in $T_{r e}$ before exercise in each season. $T_{r e}$ postexercise in winter after prewarming was not significantly different from in summer. $S$ in summer was not significantly different from $S$ in winter after prewarming: $-12.5(4.5) v-5.3(9.5) \mathrm{W} \cdot \mathrm{m}^{-2}$, respectively.

The comprehensive data in experiment 2 giving the relations between TSR, $T_{\text {re }}$, and $\bar{T}_{s}$ at rest and at three different workloads $(40,60$, and $\left.80 \% \quad \mathrm{VO}_{2} \max \right)$ at $\mathrm{T}_{\mathrm{a}}$ of 30 and $40^{\circ} \mathrm{C}$ in summer and winter following prewarming are presented in fig 3 . The thermoregulatory responses are described on the basis of the workloads (\% of $\mathrm{VO}_{2} \max$ ) (fig $3 \mathrm{~A}$ ) and the $\mathrm{T}_{\mathrm{a}}$ (fig $3 \mathrm{~B})$. At $30^{\circ} \mathrm{C}$, TSRs at the various workloads were not significantly different between summer and winter after prewarming. At $40^{\circ} \mathrm{C}$ the results were similar. $T_{\mathrm{re}}$ had a control value of $37.17(0.09)^{\circ} \mathrm{C}$ and $37.07(0.09)^{\circ} \mathrm{C}$ at $30^{\circ} \mathrm{C}$, and $37.23(0.03)$ and $37.20(0.12)^{\circ} \mathrm{C}$ at $40^{\circ} \mathrm{C}$ in summer and winter after prewarming, respectively. $\mathrm{T}_{\mathrm{re}}$ did not change during the 20 min of exercise at $40 \% \mathrm{VO}_{2}$ max at $\mathrm{T}_{\mathrm{a}}$ of $30^{\circ} \mathrm{C}$ and $40^{\circ} \mathrm{C}$ in either season. At a $\mathrm{T}_{\mathrm{a}}$ of $30^{\circ} \mathrm{C}$ and a workload of $80 \% \mathrm{VO}_{2} \mathrm{max}, \mathrm{T}_{\mathrm{re}}$ increased $(\mathrm{P}<0.05)$, reaching values of $37.83(0.17)^{\circ} \mathrm{C}$ in summer and $37.92(0.10)^{\circ} \mathrm{C}$ in winter after prewarming. At a $\mathrm{T}_{\mathrm{a}}$ of $40^{\circ} \mathrm{C}$ and a workload of $80 \% \quad \dot{V O}_{2} \max , \mathrm{T}_{\mathrm{re}}$ increased $(\mathrm{P}<0.05)$, reaching values of $37.79(0.12)^{\circ} \mathrm{C}$ in summer and $37.90(0.12)^{\circ} \mathrm{C}$ in winter after prewarming. These was no significant difference in $\mathrm{T}_{\mathrm{re}}$ in summer and winter after prewarming at any workload at $40^{\circ} \mathrm{C}$. However, $\bar{T}_{s}$ was higher in summer than in winter, in spite of the thermal stimulation. In the resting condition at $30^{\circ} \mathrm{C}, \overline{\mathrm{T}}_{\mathrm{s}}$ values were $33.03(0 \cdot 16)^{\circ} \mathrm{C}(\mathrm{n}=12)$ and $34.05(0.09)^{\circ} \mathrm{C}(\mathrm{n}=12)$ in winter and summer at $30^{\circ} \mathrm{C}$, respectively. There were

Table 2 Seasonal variation of sweating responses during exercise. Values are means (SEM)

\begin{tabular}{|c|c|c|c|c|c|}
\hline & \multicolumn{5}{|l|}{ Season } \\
\hline & Winter & $\begin{array}{l}\text { Winter with } \\
\text { prewarming }\end{array}$ & Spring & Summer & Autumn \\
\hline $\begin{array}{l}\dot{\mathrm{m}}_{\mathrm{sw}}\left(\mathrm{g} \cdot \mathrm{min}^{-1}\right) \\
\mathrm{TSR}^{-1}\left(\mathrm{~m}^{-2} \cdot \mathrm{h}^{-1}\right) \\
\Delta \operatorname{TSR}(\%) \\
\Delta \operatorname{TSR}(\%) \S\end{array}$ & $\begin{array}{c}3.2(0.4) \dagger \\
108(15.7) \dagger \\
-25.8(4.3) \\
-\end{array}$ & $\begin{array}{c}5.0(0.5) \\
167(17.2) \\
- \\
+3.2(6.4)\end{array}$ & $\begin{array}{c}4.2(0.2) \\
138(14.9) \\
+1.9(6.6) \\
-9.0(5.6)\end{array}$ & $\begin{array}{c}5 \cdot 2(0 \cdot 5)^{\star \star} \\
178(26 \cdot 2)^{\star \star} \\
+21 \cdot 5(5 \cdot 0)^{\star \star} \\
+7 \cdot 7(5 \cdot 0)\end{array}$ & $\begin{array}{c}4 \cdot 3(0 \cdot 2) \\
142(11 \cdot 7) \\
+4 \cdot 9(4 \cdot 5) \\
-6 \cdot 4(4 \cdot 5)\end{array}$ \\
\hline
\end{tabular}




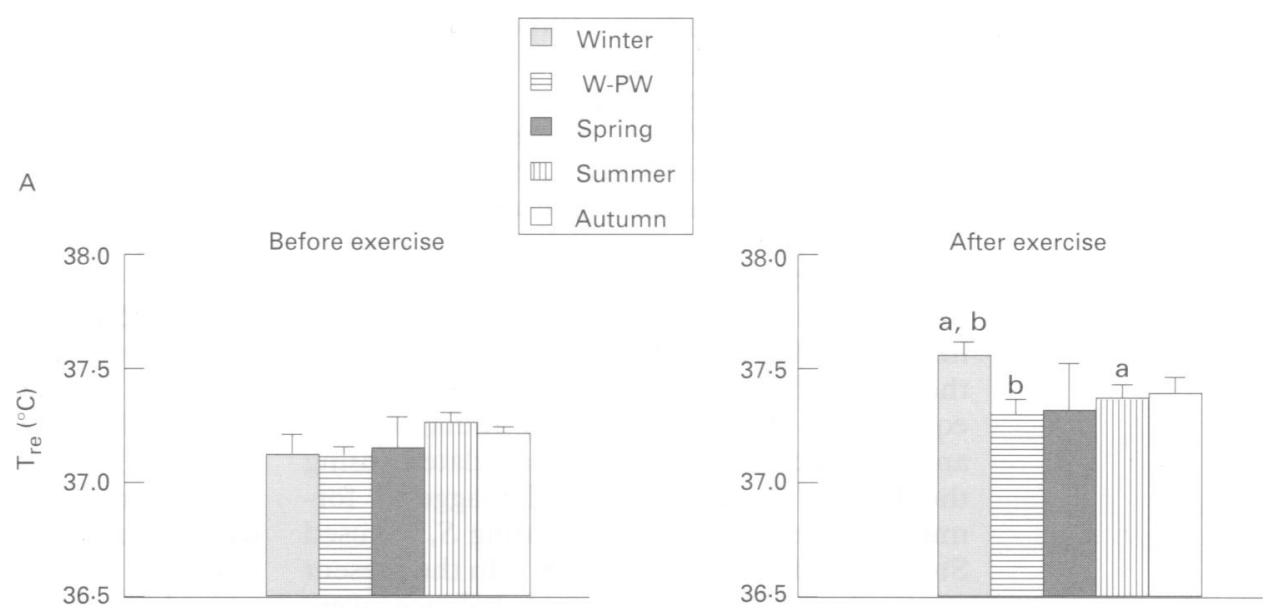

B

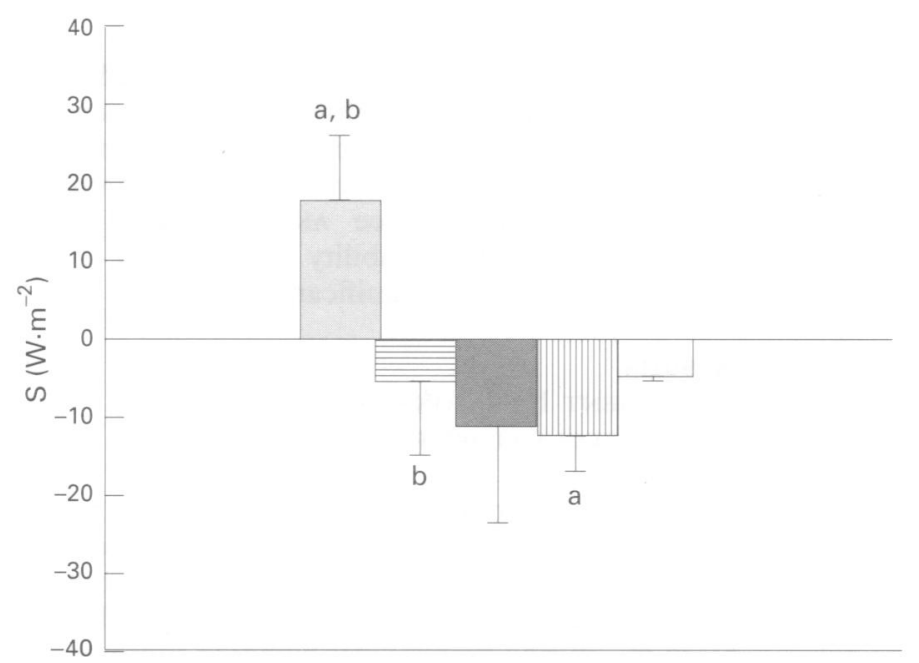

Fig 2 Rectal temperature $\left(T_{r e}\right)(A)$ and heat storage of the body $(S)$ (B) caused by exercise at $40 \%$ V $\mathrm{O}_{2}$ max in the various seasons. $W-P W$, winter after pre-warming. Significant difference, $a \mathrm{v} a$ and $b \mathrm{v} b, P<0.05$.

significant differences between $\overline{\mathrm{T}}_{\mathrm{s}}$ in winter and summer $(P<0.01)$. Conversely, $\overline{\mathrm{T}}_{\mathrm{s}}$ at $40^{\circ} \mathrm{C}$ was significantly different in winter in comparison with summer, at $35 \cdot 78(0 \cdot 11)^{\circ} \mathrm{C}(\mathrm{n}=12)$ $v 35 \cdot 13(0 \cdot 11)^{\circ} \mathrm{C}(\mathrm{n}=12)$, respectively. In all experiments $T_{s}$ during exercise decreased by about $1^{\circ} \mathrm{C}$ at any workload. TSR and the level of $\bar{T}_{s}$ were dependent on $T_{a}$, and TSR and $T_{r e}$ were dependent on the workload.

Figure 4 shows the thermal balance in the control period and during exercise at $\mathrm{T}_{\mathrm{a}} 30^{\circ} \mathrm{C}$ and $40^{\circ} \mathrm{C}$ in summer and winter after prewarming. $M$ was not significantly different in either season or temperature, but increased according to work intensity. At $30^{\circ} \mathrm{C}$ in summer and winter after prewarming, $E$ was estimated at $31 \cdot 1(2 \cdot 0)$ and $44 \cdot 0(6 \cdot 6)$, $147 \cdot 3(14 \cdot 0)$ and $143 \cdot 6(6 \cdot 2), 216 \cdot 3(20 \cdot 6)$ and $187 \cdot 4(4 \cdot 2)$, and $288.9(15 \cdot 7)$ and $253 \cdot 3$ $(25 \cdot 8) \mathrm{W} \cdot \mathrm{m}^{-2}$ at rest and at the three different work intensities of $40 \%, 60 \%$, and $80 \%$ $\mathrm{VO}_{2}$ max, respectively. At $40^{\circ} \mathrm{C}$ in summer and winter after prewarming, $E$ was estimated $96.2(4.0)$ and $80.9(8 \cdot 7), 210.0(28 \cdot 0)$ and $233.9(8.7), 276.8(5.4)$ and $292.3(4 \cdot 6)$, and $346.5(11.3)$ and $305 \cdot 8(11.9) \mathrm{W} \cdot \mathrm{m}^{-2}$ at rest and at the three different work intensities, respectively. $E$ was not significantly different in summer and winter after prewarming $(\mathrm{F}=1 \cdot 668, \mathrm{P}>0.05$, three way ANOVA, table 3$)$. $S$ was also not significantly different between summer and winter after prewarming $(\mathrm{F}=2 \cdot 439$, $P>0.05$, three way ANOVA, table 4$)$. In both seasons, $S$ levels peaked during exercise at $80 \%$ $\mathrm{VO}_{2} \max$ and $30^{\circ} \mathrm{C}$ and $40^{\circ} \mathrm{C}$. However, at a work intensity of $80 \% \dot{\mathrm{VO}}_{2} \max , S$ in winter after prewarming was significantly higher than in summer. $R+C$ values were all negative at a $\mathrm{T}_{\mathrm{a}}$ of $40^{\circ} \mathrm{C}$, and there were significant differences between $\mathrm{T}_{\mathrm{a}} 30^{\circ} \mathrm{C}$ and $\mathrm{T}_{\mathrm{a}} 40^{\circ} \mathrm{C}$, no matter

Table 3 Three way ANOVA table on the effects of season, workload, and ambient temperature ( $\left.T_{a}\right)$ on evaporative heat loss

\begin{tabular}{|c|c|c|c|c|c|}
\hline Source & $d f$ & Sum of squares & Mean square & $F$ test & Pvalue \\
\hline Season (A) & 1 & $967 \cdot 505$ & $967 \cdot 505$ & $1 \cdot 668$ & $0 \cdot 2057$ \\
\hline Workload (B) & 3 & $367088 \cdot 592$ & $122362 \cdot 864$ & $211 \cdot 017$ & 0.0001 \\
\hline $\mathrm{AB}$ & 3 & 3848.952 & 1282.984 & $2 \cdot 213$ & $0 \cdot 1058$ \\
\hline $\mathrm{T}_{\mathrm{a}}(\mathrm{C})$ & 1 & $52794 \cdot 7$ & $52794 \cdot 7$ & 91.046 & 0.0001 \\
\hline $\mathrm{AC}$ & 1 & $282 \cdot 755$ & $282 \cdot 755$ & 0.488 & $0 \cdot 49$ \\
\hline $\mathrm{BC}$ & 3 & $2203 \cdot 507$ & $734 \cdot 502$ & $1 \cdot 267$ & $0 \cdot 3024$ \\
\hline $\mathrm{ABC}$ & 3 & $2395 \cdot 022$ & $798 \cdot 341$ & $1 \cdot 377$ & $0 \cdot 2676$ \\
\hline Error & 32 & 18555.88 & $579 \cdot 871$ & & \\
\hline
\end{tabular}



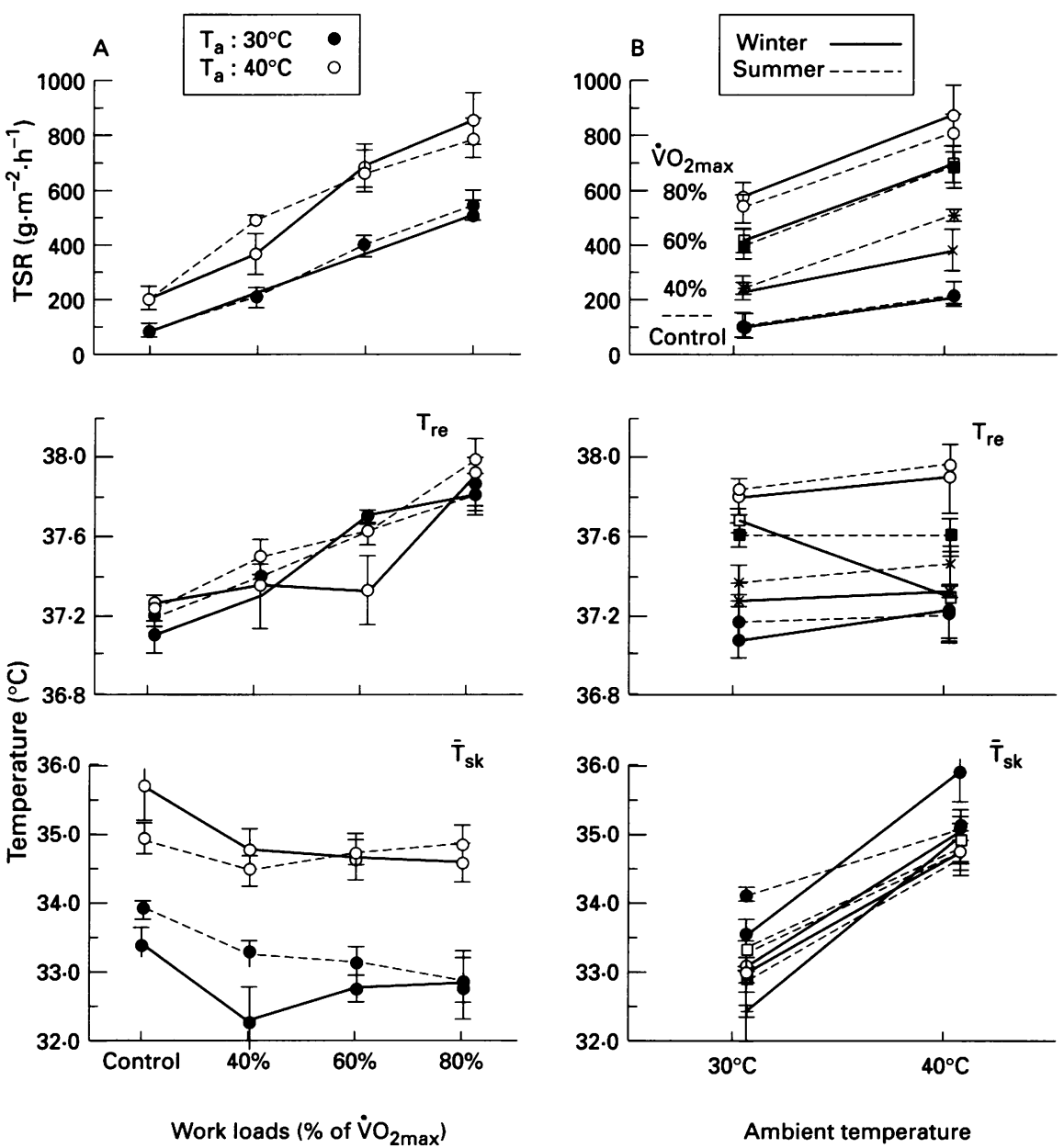

Fig 3 Comparison of total sweat rate (TSR), rectal temperature $\left(T_{\text {re }}\right)$, and mean skin temperature $\left(T_{s}\right)$ in summer $(---)$ with that in winter following prewarming $(-)$ at control (rest) and at three different workloads, 40\%, 60\%, and $80 \%$ of the individual's maximum oxygen uptake $\left(\mathrm{VO}_{2}\right.$ max) at $30^{\circ}$ and $40^{\circ} \mathrm{C}$. The thermoregulatory responses are described on the basis at the workloads $(A)$ and the ambient temperatures $\left(T_{a}\right)(B)$.

what degree the work intensity or whether summer or winter.

\section{Discussion}

Conflicting evidence has been presented on the effect of season on thermoregulatory responses during exercise, ${ }^{14529}$ and previous reports have been unable to provide an adequate explanation for the mechanism and role of seasonal acclimatisation.

In experiment 1 , the results show that the onset of sweat secretion in summer is markedly earlier than in winter. There was a significant difference in sweating patterns in the various seasons. In addition to its earlier onset, sweating also became more profuse in the warm season, even though the subjects were exercising under the same environmental conditions, as pointed out previously by Kuno. ${ }^{20}$ Furthermore, $\triangle T S R$, the change in the annual

Table 4 Three way ANOVA table on the effects of season, workload and ambient temperature $\left(T_{a}\right)$ on heat storage of the body

\begin{tabular}{lrrrrl}
\hline Source & $d f$ & Sum of squares & Mean square & \multicolumn{1}{c}{ F test } & Pvalue \\
\hline Season (A) & 1 & 975.603 & 975.603 & 2.439 & 0.1282 \\
Workload (B) & 3 & 30374.605 & 10124.868 & 25.31 & 0.0001 \\
AB & 3 & 1164.945 & 388.315 & 0.971 & 0.4186 \\
$T_{2}(C)$ & 1 & 279.367 & 279.367 & 0.698 & 0.4095 \\
AC & 1 & 632.201 & 632.201 & 1.58 & 0.2178 \\
BC & 3 & 546.618 & 182.206 & 0.455 & 0.7153 \\
ABC & 3 & 1944.614 & 648.205 & 1.62 & 0.204 \\
Error & 32 & 12801.193 & 400.037 & & \\
\hline
\end{tabular}

mean total sweating rate, presented a typical pattern with summer high and winter low values, and the percentage deviation from the annual mean was $+21 \cdot 5(5 \cdot 0) \%$ in summer and $-25.8(4.3) \%$ in winter. The annual rage of $\Delta$ TSR was reduced by prewarming in the cold season (table 2). We accept the concept proposed by Sasaki et $a l^{30}$ to explain the mechanism of the annual periodicity of basal heat production in the Japanese. Clearly, the sweating rate, described as a relative value, can result in annual variation of sweating response under conditions of temperature and seasonal acclimatisation.

These results may imply that the sweating capacity and sensitivity in summer are greater than in winter, and there is natural seasonal acclimatisation of physiological function in humans to inhibit the dissipation of heat from the body in winter. In contrast, these functions may be attenuated in summer, in order to minimise heat storage by the body (fig 2B). The data from experiment 1 may reflect the fact that there is such a functional change in thermoregulatory mechanisms to seasonal temperature acclimatisation in the exercising human. We therefore compared thermal balance under submaximal exercise conditions in winter after prewarming and in summer.

The objective of experiment 2 was to assess whether $m_{s w}$ and sweating sensitivity in the cold 

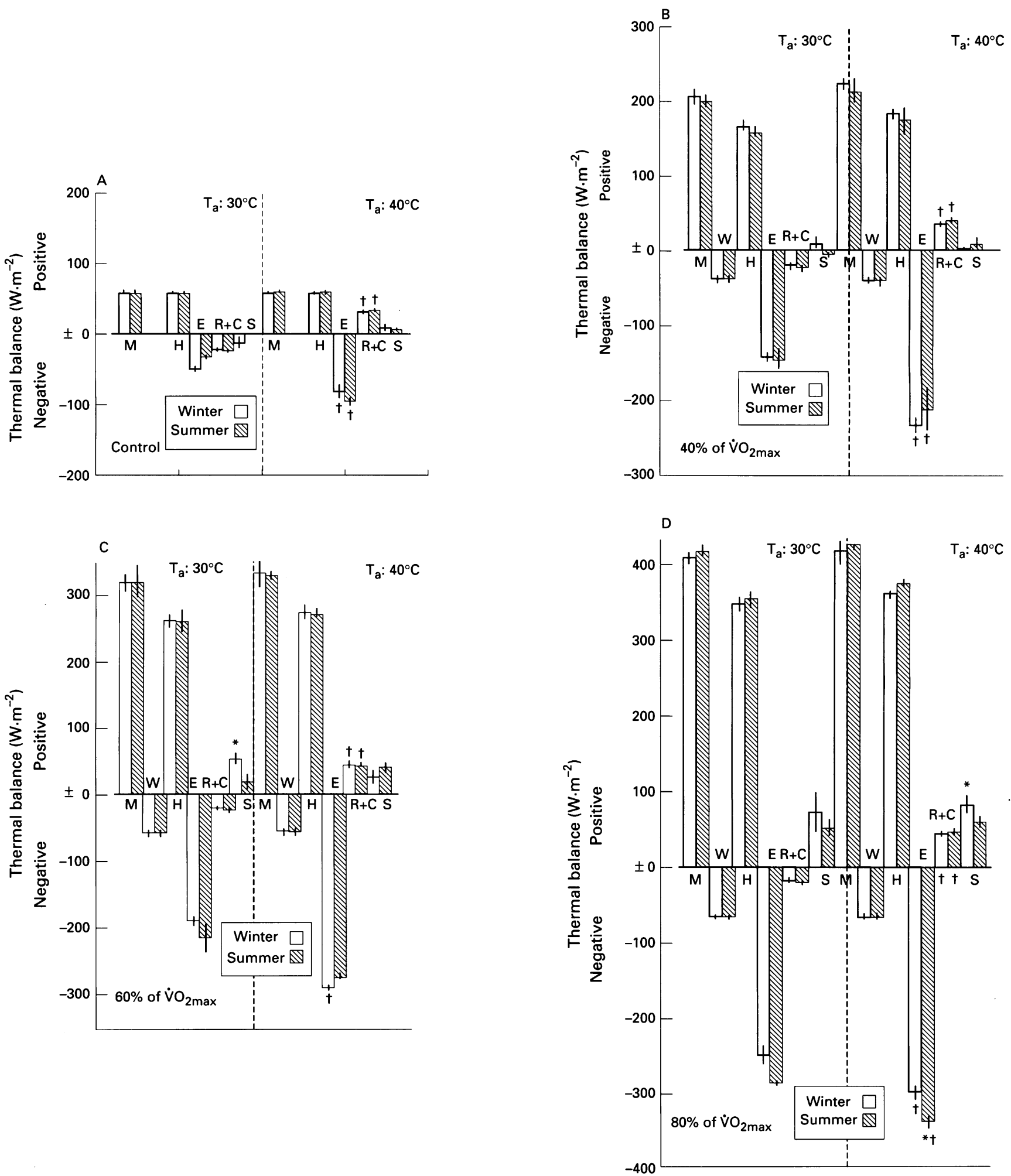

Fig 4 Thermal balance at rest (A, Control) and during exercise of $40 \%(B), 60 \%(C)$, and $80 \%(D)$ of $\dot{V O}_{2}$ max at $T_{a}$ of $30^{\circ} \mathrm{C}$ and $40^{\circ} \mathrm{C}$ in summer $(\mathbb{\nabla})$ and winter $(\square)$ after prewarming. $\mathrm{M}$, metabolic rate; $\mathrm{W}$, external work; $\mathrm{H}$, total heat production; $\mathrm{E}$, evaporative heat loss; $\mathrm{R}+\mathrm{C}$, radiative and convective heat loss; $\mathrm{S}$, change in heat storage of the body.

Significant difference between summer and winter after prewarming, ${ }^{\star} P<0.05$; significant difference, $+P<0.05, T_{a} 30^{\circ} \mathrm{C} \vee T_{a} 40^{\circ} \mathrm{C}$.

season can be enhanced by means of warming before exercise. The lack of seasonal difference in the sweating pattern during exercise in winter and summer when thermal stimulation of $30^{\circ} \mathrm{C}$ for 30 minutes (prewarming) was applied in winter was of interest. Many investigators ${ }^{7-10}$ have shown that enhancement of skin sweating results from physical training by an increase in the sensitivity of the skin sweating response per unit of internal temperature rise, and heat acclimatisation by a decrease in sweating. It has been reported that during continuous exposure to severe heat, the sweating rate increases to a maximum. ${ }^{31}$ $\mathrm{Nadel}^{32}$ stated that during muscular activity, heat flows down the temperature gradient from the muscle to the body core and to the skin; that is, from where it can dissipate into the 
environment. However, when environmental temperature is higher than skin temperature, heat transfers from the environment into the body. The rate of sweating becomes enhanced to meet the requirement of cooling when thermal stress and workload increase. Thermal stimuli evoke thermoregulatory responses that directly affect heat loss and heat production. Thus by prewarming we found that thermal stimulation helped the evaporation of sweat from the skin more in winter than in summer, showing an enhancement $\mathrm{m}_{\mathrm{sw}}$ and sweating sensitivity in winter; in the cold season the evaporative losses are activated to the "summer type". This implies that operation of the heat dissipation centre in the hypothalamus may be induced through skin thermoreceptors activated by thermal stimulation. ${ }^{33} \mathrm{Kuno}^{20}$ has suggested that changes in the sensitivity in the central nervous system may be most the important factor. However, repeatedly warming localised areas of the skin has been found to enhance sweating from the warmed areas, ${ }^{15}$ and it can be inferred that increase in sweating capacity is, at least in part, a peripheral effect caused by changes in the sweat glands. In addition, by local passive heating of the body surface, forearm blood flow and sweat gland activity in this region were markedly enhanced. ${ }^{34}{ }^{35}$ Further studies are required to clarify these matters.

As previously reported by Hardy et al,,$^{36}$ there were linear correlations between sweat rate and increase of rectal temperature, and sweat rate and the level of skin temperature (fig 3). The two major independent experimental variables in evaluating the effect of exercise on temperature regulation are the temperature of the environment and the workload. Our data illustrated in fig 3 show how these two variables cause changes in regulatory sweating, core temperature, and skin temperature. Saltin et $a l^{37}$ showed that regulatory sweating can be predicted by a linear regression analysis with workload (or metabolic heat production) and ambient temperature, and these, taken together, represent the thermal load; this balance indicates the complete effectiveness of thermoregulation under these conditions. Benzinger ${ }^{38}$ found that sweat rate was entirely dependent on the degree of elevation of the internal temperature, which he measured at the tympanic membrane, provided that mean skin temperature was above $33^{\circ} \mathrm{C}$. The relation between the internal temperature and $\dot{\mathrm{m}}_{\mathrm{sw}}$ was the same, whether body temperature was raised by exposing the subject at rest to a hot climate or by metabolic heat production.

On the other hand, basal metabolism in Japan has been found to have seasonal variation, high in winter and low in summer. ${ }^{39}$ Many researchers have investigated the effect of seasonal and other factors on heat production during exercise. ${ }^{124}$ According to Nielsen, ${ }^{40}$ the rate of heat production caused by muscular exercise is more closely related to workload than to ambient temperature, and there is a significant correlation between increase in core temperature and in the rate of heat production. Moreover, Saltin and
Hermansen ${ }^{41}$ have shown that the increase in core temperature is proportional, not to the absolute value of metabolic rate, but to the relative workload, that is, to the percentage of the individual's $\mathrm{VO}_{2}$ max. It has previously been reported by Masuda $^{29}$ that heat production during exercise at a relative metabolic rate of 5 to 8 was not affected by season. Matsui et $a l^{3}$ have investigated $\dot{\mathrm{VO}}_{2}$ max for each season in the year, and they found no significant relation with season. Although cardiac output, stroke volume, and heart rate were significantly decreased with higher ambient temperature $\left(T_{a} 43.3^{\circ} \mathrm{C}\right)$, oxygen uptake during exercise was unaffected..$^{42}$ In the present study, the workloads were $40 \%, 60 \%$, and $80 \%$ of $\mathrm{VO}_{2}$ max throughout the year. Moreover, no circadian difference was observed in metabolic heat production, while workload level and circadian variation affected sweat rate, $T_{\mathrm{re}}$, and mean body temperature. ${ }^{43}$ Thus, assuming that metabolic heat production, for a constant work intensity, is at least at the same level in each season (fig. 4), the rise in the core temperature in summer may be considered to be similar to that in winter. We assumed that the thermal body warming conducted before exercise in the cold season activated the heat dissipating mechanisms. As stated above, our data suggest that sweating may be facilitated not only by a hypothalamic mechanism, from thermal information received from the skin thermoreceptors, but also by increased activity of the peripheral sweat glands.

Skin temperature control in humans has been shown to be the result of many factors. ${ }^{23}$ The factors that affect the skin temperature are very complex and include core temperature, vasoconstriction and vasodilatation, blood flow, and ambient temperature (including the air velocity). In this study, we observed that an increased workload produced a proportional reduction in skin temperature in cool environments $\left(10^{\circ} \mathrm{C}\right.$ and $\left.20^{\circ} \mathrm{C}\right)$. The fall in skin temperature is closely related to both nonthermal and thermal factors, such as evaporative heat loss. ${ }^{44}$ However, in our study there was a fall in skin temperature during exercise at all workloads, and the fall was independent of the season and work intensity (figs 2 and 3). We also concluded that the skin temperature during exercise was modified as a result of competition between thermoregulatory vasodilatation and reflex induced vasoconstriction by regulatory factors imposed by the environmental temperature conditions. Nakayama et al $^{45}{ }^{46}$ have published a hypothesis on thermoregulatory mechanisms in the exercising human. If skin temperature does not change during physical exercise this is because of the competitive action between non-thermal vasoconstriction, thermal vasodilatation, and evaporation. On the other hand, if non-thermal vasoconstriction does not occur during exercise, internal temperature, with enhancement of heat dissipation function, does not increase through the exercise period. Thus the regulating mechanisms for increasing core temperature during physical exercise inhibit, at least in part, heat dissipation occurring by non-thermal 
vasoconstriction due to the exercise. We agree with their hypothesis on thermoregulatory mechanisms during exercise.

Recently, the significance of exercise for a healthy life has been recognised worldwide but there is little practical knowledge about physiological thermoregulatory function in humans, especially as it is affected by temperature conditions and exercise. We determined that the maximum rate of sweating is controlled by both work intensity and humidity in moderate temperature conditions. The former contributes to reduced heat loss and the latter to increased metabolic heat production. The maximum sweating capacity in humans is observed in prolonged moderate muscular exercise under thermal stress, namely, internal and external heat loads. ${ }^{31}$ It is induced by 60 to 240 minutes of muscular activity such as walking in the desert and simulation of severe exercise ( $>80 \%$ of maximum aerobic capacity). Thus the exercising human is affected by seasonal factors, and in the prescription of exercise programmes attention must be paid to such factors as exercise intensity, frequency, and duration. Indeed, exercise performance is influenced by environmental temperature, since it represents an extra load on the circulatory and thermoregulatory mechanisms, but internal temperature affects physical performance as well. ${ }^{14}$ The beneficial effect of warm up has been known for a long time and was determined experimentally, for example, by Asmussen and Bøje, ${ }^{47}$ who showed that the ability to perform running was better. Warm up has contributed to an increase in exercise performance and to a reduction in accidents caused by exercise and sports activity. This evidence may be important in evaluating the effectiveness of a physical training programme.

In conclusion, our findings suggest that adaptation of the thermoregulatory mechanisms during temperature and seasonal acclimatisation exists, and that external body warming enhances not only the heat dissipating activity of the thermoregulatory centre but also the induction of peripheral sweat gland activity. Furthermore, the seasonal change of $\mathrm{m}_{\mathrm{sw}}$ in exercising men can be eliminated by prewarming in the cold season, suggesting a different type of acclimatisation. Our experimental results indicate that very rapid acclimatisation is possible.

We wish to thank the subjects for their enthusiastic participation in these experiments. The work was supported by a grant from the MEISENKAI, the Kyushu Institute of Technology Graduate's Association. We would like to thank Prof $H$ Nakayama (Department of Hygiene, Faculty of Medicine, Tottori University) and Prof Y Hiji and Prof Y Kawai (Department of Physiology, Faculty of Medicine, Tottori University) for their valuable comments and critical reading of the manuscripts, and Dr S Morio, Dr M Okamoto, and Dr A Suyama (Department of Hygiene, Faculty of Medicine, Tottori University) for their helpful advice. We would also like to thank $\mathrm{Dr} M$ Orleans, visiting professor in the Kyushu
Institute of Technology, for checking the English, and Ms M WaTanabe and Ms M Iwamoto (Department of Hygiene, Faculty of Medicine, Tottori University) for their valuable technical and secretarial assistance. This work was partly presented in the XXIV FIMS World Congress of Sports Medicine, Amsterdam, 1990,48 and the 2nd International Congress of Physiological Anthropology, Kiel, 1994. ${ }^{49}$.

1 Gold AJ, Zornitzer A, Samueloff S. Influence of season and heat on energy expenditure during rest and exercise. heat on energy expenditure
2 Yasuda Y, Miyamura M. Seasonal variation of forearm blood flow at rest and during submaximal exercise. 7 Physiol Soc fapan 1983;45:640-3.

3 Matsui H, Shimaoka K, Miyamura M, Kobayashi K Seasonal variation of work capacity in ambient and constant temperature. In: Folinsbee LJ, et al eds. Environmental stress, individual human adaptations. New York: Academic Press, 1978:279-90.

4 Araki T, Matsushita K, Umeno K, Tsujino A, Toda Y Effect of physical training on exercise-induced sweatin in women. $\mathcal{F}$ Appl Physiol: Respir Environ Exercise Physiol 1981;51:1526-32.

5 Shapiro Y, Hubbard RW, Kimbrough CM, Pandolf KB. Physiological and hematologic responses to summer and winter dry-heat acclimation. 7 Appl Physiol: Respir Environ Exercise Physiol 1981;50:792-8.

6 Hori S, Inouye A, Ihzuka H, Yamada T. Study on seasonal variations of heat tolerance in young Japanese males and effects of physical training thereon. $\Im p n \Im$ $\Im$ Physiol 1974; 24:463-74

7 Wyndham CH, Strydom NB, Benade AJS, Van Rensburg AJ. Limiting rates of work for acclimatization at high wet bulb temperatures. $\mathcal{F}$ Appl Physiol 1973;35:454-8.

8 Robinson S, Turrell ES, Belding HS, Horvath SM. Rapid acclimatization to work in hot climates. Am $\mathcal{f}$ Physiol 1943;140:168-76.

9 Nadel ER, Pandolf KB, Roberts MF, Stolwijk JAJ. Mechanisms of thermal acclimation to exercise and heat. f Appl Physiol 1974;37:515-20.

10 Strydom NB, Wyndham CH, Williams CG, Morrison JF, Bredell GAG, Banande AJS, Von Rahanen $M$ Acclimatization to humid heat and the role of physical conditioning. F Appl Physiol 1966;21:636-42.

11 Barcroft H, Bock KD, Hensel H, Kitchin AH. Die Muskeldurchblutung des Menschen bei indurekter Erwärmung und Abkühlung. Pfügers Arch 1955;261: 199-210.

12 Wenger CB, Roberts MF, Stolwijk JAJ, Nadel ER. Forearm blood flow during body temperature transients produced blood flow during body temperature transien

13 Johnson JM, Brengelmann GL, Rowell LB. Interactions between local and reflex influences on human forearm between local and reflex influences on human
skin blood flow. $\mathcal{F}$ Appl Physiol 1976;41:826-31.

14 Nadel ER, Cafarelli E, Roberts MF, Wenger CB. Circulatory regulation during exercise in different ambient temperatures. $\mathcal{F}$ Appl Physiol: Respir Environ Exer Physiol 1979;46:430-7.

15 Ogawa T, Asayama M, Miyagawa T. Effects of sweat gland training by repeated local heating. Fpn f Physiol 1982 32:971-81.

16 Torii $M$, Nakayama $H$. Disappearance of seasonal variation of sweating responses in exercising man: effect of preheating in cold season. $\mathcal{f}$ Hum Ergol 1993;22:11-20.

17 Takahira H. A study of metabolic rate in the Japanese; surface area in the Japanese and its estimation equation. Eiyo Kenkyusho Hokoku 1925;1:61-95 (in Japanese).

18 Miyamura $M$, Honda $Y$. Oxygen intake and cardiac output during maximal treadmill and bicycle exercise. $\mathcal{J} A p p l$ during maximal treadmill

19 Sasaki T. Circadian rhythm in body temperature. In: Itoh S, Ogata $\mathrm{K}$, Yoshimura $\mathrm{H}$, eds. Advances in climatic physiology. Tokyo: Igaku Shoin, 1972:319-33.

20 Kuno Y. Human perspiration. Springfield: CC Thomas, 1956.

21 Saltin B, Gagge AP, Stolwijk JAJ. Body temperatures and sweating during thermal transients caused by exercise. 7 Appl Physiol 1970;28:318-27.

22 Mitchell JW, Nadel ER, Stolwijk JAJ. Respiratory weight losses during exercise. F Appl Physiol 1972;32:474-6.

23 Houdas Y, Ring EFJ. Human body temperature, its measurement and regulation. New York: Plenum Press, 1982.

24 Hardy JD, DuBois EF. The technique measuring radiation and convection. $\mathcal{F}$ Nutr 1938;15:461-75.

25 Stolwijk JAJ, Hardy JD. Partitional calorimetric studies of responses of man to thermal transients. $\mathcal{F}$ Appl Physiol 1966;21:967-77.

26 Nielsen B. Thermoregulation in rest and exercise. Acta Physiol Scand Suppl 1969;323:1-74.

27 Fanger PO. Thermal comfort. Copenhagen: Danish Technical Press, 1970.

28 Nishi Y, Gagge AP. Direct evaluation of convective heat transfer coefficient by naphthalene sublimation. F $A p p l$ Physiol 1972;29:830-8.

29 Masuda G. Studies on annual periodicity of energy metabolism, reports 2. effect of season of energy metabolism during exercise. Bull Inst Constit Med Kumamoto Univ 1967;17:173-9 (in Japanese with English abstract).

30 Sasaki T, Yasumoto I, Minakami M, Inoue T, Ishihara A, Taniguchi $M$. Seasonal observation in thermal balance in basal state. Bull Inst Constit Med Kumamoto Univ 1969;20:72-8 (In Japanese with English abstract).

31 Torii M. Human sweating. In: Seki K, et al, eds. Handbook of physiological and psychological tolerance limits in man. Tokyo: Asakura Shoten, 1990:55-66 (in Japanese).

32 Nadel ER. Control of sweating rate while exercising in the heat. Med Sci Sports 1979;11:31-5.

33 Hensel H. Thermoreceptors. Annu Rev Physiol 1974;36: 233-49.

34 Barcroft $\mathrm{H}$, Edholm OG. Temperature and blood flow in the human forearm. I Physiol (Lond) 1946;104: 366-76.

35 Edholm OG, Fox RH, Macpherson RK. The effect of body heating on the circulation in skin and muscle. $\mathcal{F}$ Physiol (Lond) 1956;134:612-9. 
36 Hardy JD, Stolwijk JAJ, Gagge AP. Man. In: Whittow GC, eds. Comparative physiology of thermoregulation. Vol. 2. Mammals. New York: Academic Press, 1971:327-80.

37 Saltin B, Gagge AP, Stolwijk JAJ. Muscle temperature during submaximal exercise in man. $\mathcal{f}$ Appl Physiol 1968;25:679-88.

38 Benzinger TH. Heat regulation: homeostasis of central temperature in man. Physiol Rev 1969;49:671-759.

39 Sasaki, T. Relation of basal metabolism to changes in food composition and body composition. Fed Proc 1966;25: 1165-8.

40 Nielsen $\dot{M}$. Die Regulation der Körpertemperatur bei Muskelarbeit. Skand Arch Physiol 1938;79:193-230.

41 Saltin B, Hermansen L. Esophageal, rectal, and muscle temperature during exercise. $\mathcal{F}$ Appl Physiol 1966;21: 1757-62.

42 Rowell LB, Marx HJ, Bruce RA, Conn RD, Kusumi F Reductions in cardiac output, central blood volume, and stroke volume with thermal stress in normal men during exercise. F Clin Invest 1966;45:1801-16.
43 Torii $M$, Nakayama H, Sasaki T. Thermoregulation of exercising men the morning rise and evening fall phases of internal temperature. Br F Sports Med 1995;29:113-20.

44 Torii $M$, Yamasaki M, Sasaki T, Nakayama H. Fall in skin temperature of exercising man. Br $\mathcal{F}$ Sports Med 1992; 26:29-32.

45 Nakayama T, Ohnuki Y, Niwa K. Fall in skin temperature during exercise. Ipn $\mathcal{F}$ Physiol 1977;27:423-37.

46 Nakayama $T$. Human body and its regulating mechanisms - set point of internal body temperature. In: Utsunomiya T, ed. Systematic control of human body. Tokyo: Asakura Shoten, 1977:253-9 (in Japanese).

47 Asmussen E, Bøje O. Body temperature and capacity for work. Acta Physiol Scand 1945;10:1-22.

48 Torii M, Yamasaki M, Sasaki T. Exercise-sweat rate in winter can be enhanced by pre-heating. XXIV FIMS World Congress of Sports Medicine [abstr], 1990:161.

49 Torii M, Nakayama H, Yamasaki M, Sasaki T. Facilitatory effect of pre-warming on exercise-sweat rate in winter. Proceedings of 2nd International Congress on Physiological Anthropology, 1994:128-31.

\title{
1996 BASM ANNUAL CONGRESS
}

Thursday 31 October-Sunday 3 November at

Newcastle, Co Down, Northern Ireland

\section{SPORTS MEDICINE INTO THE 21st CENTURY}

\author{
Keynote speakers: \\ Prof Per Renström \\ Vermont, USA \\ Prof David Costill \\ Indiana, USA \\ Dr Willem van Mechelen Amsterdam, Holland
}

\section{Topics will include:}

- Physiological, psychological and pharmacological limits to performance in sport, physical activity and health - new challenges for the health carers.

- The ankle - a complete overview of acute, recurring and chronic injury and its rehabilitation.

- Advances in imaging.

- Pre-hospital care of the acutely injured sportsman.

Scientific papers and posters will be presented and displayed. We are now looking for abstracts.

For further information regarding the scientific programme, abstract submission or booking arrangements please contact:

\author{
Dr Robin Harland MB FRCGP FISM \\ 6 Castlehill Road \\ BELFAST BT4 3GL \\ Northern Ireland \\ Telephone: 01232653682 Fax: 01232473540 \\ E-Mail: R.Harland@QUB.AC.UK
}

The setting for the 1996 Conference is in an area of outstanding beauty with facilities for many sporting activities. This is a perfect opportunity to combine a Conference of high standard with a short break in a new setting and to experience our famous Irish hospitality.

Full PGEA approval sought. 